\title{
An Overview of the Pidgin English in Cameroon
}

\author{
Beatrice Ekanjume-Ilongo (PhD) \\ National University of Lesotho \\ bilongo.ekanjume@yahoo.com,b.ekanjume@nul.ls
}

\begin{abstract}
Cameroon, like some African countries, has a complex language situation in the sense that in addition to the two official languages (French and English), many indigenous languages do exist. Because of this linguistic diversity, Cameroonians have devised a means of a common linguistic identity - Cameroon Pidgin English (CPE) - through which they can understand each other. The paper shows that CPE is viable, flexible and practical, and that Cameroonians are more comfortable using this language, which they consider to be an indigenous language, than using either French or English the official languages. Another claim in this paper is that Cameroonians consider CPE as a more natural and unifying language which "grows" in their eyes and which transcends geographical and political boundaries, because it is not a language of a particular ethnic group and thus goes beyond the reproach of tribalism. The paper argues that if there are enough written material and text books on CPE, it will be an appropriate language for use as a medium of instruction in the early years of schooling and for the education of Cameroonian adult illiterates.
\end{abstract}

Keywords: Cameroon, Pidgin English, Language, Communication, Linguistic diversity.

\section{INTRODUCTION}

Pidgins are languages that are often despised and looked down upon in social policy settings (language-in-education policies in particular and national language policies in general). Like other emergent and reticent languages all over the world, pidgins (and creoles) do not enjoy the prestigious official status accorded other varieties of language in national language policy regimes of those nation-states in which they are spoken. Pidgins are often erroneously considered incomplete, broken, corrupt and not worthy of serious attention. However, while these attitudes are still prevalent even in academic circles and in society, their significance for ethnic, immigrant and other social groups, as well as for various political projects is now widely acknowledged. Many scholars have been working on Cameroon Pidgin English (CPE) and this stems as far back as the mid 1960s.

Cameroon is a multilingual country consisting of two official languages (English and French), and according to Grimes (2002), over 286 local languages. In addition to these, there exist lingua francas, with the most widely used being the CPE. Due to the intense multilingual nature of the country, there is a lot of linguistic borrowing, interference, code mixing, code switching, loan translation, and other manifestations of language contact. As a result, the languages mutually exert some influence on one another Echu (2004: 22).

CPE is referred to by some scholars as 'Kamtok' which is derived from 'Cameroon-talk' (see Todd, 1984; and Todd and Jumban, 1992). It can be said to have about five varieties, based on regional differences. These include:

- The 'Grafi Pidgin English', which is a variety spoken in the grassfields region of Cameroon. It is therefore derived from the word 'Grassfield' and is often referred to as 'Grafi Talk'.

- The Liturgical Pidgin, English which is a variety that has been used by the Catholic Church for almost a century.

- The 'Francophone Pidgin English', which is a variety used mainly in French speaking towns such as Bafoussam, Douala and Yaoundé and by Francophones talking to Anglophones who do not speak french.

- The 'Coastal Pidgin English', which is a variety spoken mainly in the southwest region of Cameroon. 
- The 'Bororo Pidgin English' which is a variety spoken by the Bororo cattle traders (many of whom travel through Nigeria and Cameroon) and in the Northern and Adamawa regions of Cameroon.

CPE is an English-based creole. According to Neba et al (2006: 41), about 5 percent of Cameroonians are native speakers of the language, while an estimated 70 percent of the population speaks it in some form. It is a variety of West African Pidgin Englishes spoken along the coast from Ghana to Cameroon.

\section{A BRIEF History Of THE NatURe OF LANGUAges in CaMeroon 2.1. Official Languages}

During the First World War, Germany was defeated and sent out of the territories that the Germans were occupying. One of them was Cameroon. After the defeat of Germany, Britain and France divided Cameroon into two unequal parts in 1916. Following this division, the new colonial masters decided to impose their languages in the newly acquired territory, both in the areas of education and administration. Therefore, between 1916 and 1960 English and French were solidly implanted in Cameroon. This situation was later reinforced after Cameroon became independent in 1961, whereby English and French became the two official languages of Cameroon as the country opted for the policy of official language bilingualism.

At independence, English and French were logically adopted as the official languages of the country, because the linguistic diversity of the country did not permit the emergence of an indigenous language to play the role of an official language. The two languages were thus chosen for reasons of national unity, since the English speaking Cameroonians considered themselves as Anglophones and the French speaking ones as Francophones. The two languages became the languages of education, administration, politics, culture, the media etc. Consequently, they became the language of communication for a large component of the population.

As official languages of the country, English and French are acquired primarily within the formal school environment. This is supported by Chumbow and Simo-Bobda (2000: 46) who state that the literacy rate of the country stands at 65 percent and the school attendance rate that stands at 70 percent. In addition to the formal acquisition of these languages, some Cameroonians who live in urban centers can also speak English or French acquired mainly in informal situations. Thus, in the absence of a national language that ensures nationwide communication, French and English languages function as languages of wider communication in towns and cities of the Francophone and Anglophone parts of the country respectively. However, there are several Cameroonians who can neither speak French nor English. The only languages that such Cameroonians speak are their mother tongue and/or CPE. This implies that they can only communicate either by using their mother tongue or the CPE.

\subsection{Indigenous Languages}

Cameroon is a multilingual nation of about 22 million people who speak over 250 indigenous languages (Kouega, 2007). According to Echu (1999), the over 250 indigenous languages of Cameroon fall within three of the four major language families of Africa namely the Afro-Asiatic, the Nilo-Saharan and the Niger Kordofanian families. The Niger-Kordofanian family is the most highly represented, while the Khoisan family is not represented at all. Despite the multilingual nature of Cameroon, the government is doing very little to promote the indigenous languages.

However, in spite of the relative silence on the part of the State as regards indigenous languages, experimental projects in the area of teaching and research have long been carried out through private initiative with the implicit approval of government authorities. Such initiatives are observed through the action of Summer Institute of Linguistics (SIL) -Cameroon, PROPELCA (Operational Research Program for Language Teaching in Cameroon), Cameroon Association for Bible Translation and Literacy (CABTAL), and National Association of Cameroonian Language Committees (NACALCO), and others. Unfortunately, indigenous languages continue to be completely absent from the school curriculum in spite of the fact that "the early use of the mother tongue in education has significant long term benefits with respect to maximising the development of the intellectual potential of the child" (Chumbow 1996: 5). Unfortunately, the teaching of indigenous languages, as proposed by PROPELCA, does not always meet with the approval of the population. Studies reveal that parents have a negative attitude towards the use of indigenous languages as a means of instruction (Tadadjeu 1990: 126). 
Experience has shown that most parents in Cameroon seem to be generally hostile towards the introduction of early childhood education in the indigenous languages. Several parents send their children to nursery schools as early as the age of three, where the language of communication is English or French. It is obvious that parents who expose their children at an early age to the official language will be totally against the introduction of indigenous languages in the early years of primary education. Such unfavourable attitudes do not predict well for the introduction of indigenous languages in the school system. The nursery schools, it should be noted, very often follow foreign models of education in terms of pedagogic and cultural material used. This attitude according to Adegbija (2000: 84), ties up with the view that West African countries formerly colonised by the French are still largely dependent linguistically and culturally, a dependency attitude that has dangerously impeded the growth of their indigenous languages. Thus, Cameroon, unlike some other Sub-Saharan African countries, where the indigenous languages are used as the medium of education in the first three years of primary education, still uses exclusively the two official foreign languages at all levels of education. In view of this situation, attitudes towards the official languages are positive, whereas they are negative towards the indigenous languages. Adegbija (2000: 84) supports this by saying that:

\begin{abstract}
In fact, in schools in many former French and Portuguese colonies, indigenous languages are not tolerated at all even at primary school level, partly because the present level of language development efforts makes this impossible and also partially because of the clamour of parents for their children to be introduced to European languages as early as possible.
\end{abstract}

\title{
3. Origins of Cameroon Pidgin English
}

Pidgin English has been used in Cameroon for several years now. As Kouega (2007: 6) says, Pidgin English came into being in the Slave Trade Years (1400-1800). The first Baptist missionaries, who came to Cameroon in 1845 and introduced formal education in English, had to learn Pidgin. A few decades later, during the German annexation period (1884-1914), Pidgin resisted a German ban. It took flight when it became a makeshift language used in German plantations and undertakings by forced labourers who were drawn from the hinterland and who spoke different indigenous languages. With time, it invaded the market place and was adopted by Baptist missionaries as the language of their evangelical crusade. For many years, it has been used on school playgrounds and campuses and in political campaigns. Today it is forcing its way into the spoken media scene.

As mentioned earlier, studies on CPE stem as far back as 1960 with scholars who gave the language various appellations. According to Ayafor (2006) some scholars have called the language 'Cameroon Creole', 'Wes-Kos, and 'West African Pidgin English'. Todd (1992: 4) on the other hand called it 'Cameroon Pidgin (CamP)'; while Todd (1984) quoted by Ngome (1986) called it 'Kamtok'. Based on the widespread belief that Pidgin English (be it of the Cameroonian variety or other existing varieties such as Nigerian Pidgin English and Ghanaian Pidgin English) is a simplified form of the English Language used mostly by non-educated people in some of the former British colonies of West Africa, some non-scholarly appellations such as 'bush English', 'bad English' and 'broken English' have equally been used to refer to this language. The name "Cameroon Pidgin English" (Féral, 1989: 44) has so far gained a lot of popularity at the level of scholarship and consequently most linguists carrying out research on Cameroon today have adopted it. The adoption of this terminology makes it relatively easier to define this language as the Pidgin English used in Cameroon, as opposed to varieties used in other countries. It is however important to note that the varieties used in other countries (Ghana and Nigeria) are mutually intelligible to the CPE.

According to Echu (2004: 20) the birth of CPE is often traced as far back as the $18^{\text {th }}$ century when English traders and missionaries set foot on the coast of West Africa. Pidgin English developed to guarantee effective communication in the area of trade and evangelization. After the abolition of slave trade at the beginning of the 19th century, this language continued to expand all over the coastal region. It was used by some of the newly freed slaves who settled in Fernando Po, Liberia and Sierra Leone, and later moved to the Cameroonian coastal town of Victoria where they worked for the Cameroon Development Corporation (an agro- industrial complex created by the Germans in 1884). The numerous road and railway construction projects where the colonialists practised forced labour also served as a fertile ground for the growth and development of CPE. Given that these work sites 
brought together people from diversified ethnic and linguistic backgrounds, Pidgin English was the only language that could facilitate communication (Kouega 2007: 6).

In British Cameroon, where it was mainly spoken, English and the indigenous languages enriched its vocabulary. Then with the birth of the Federal Republic of Cameroon on October 1, 1961, CPE further experienced French influence, as well as influence from the local languages of Frenchspeaking Cameroon. Thus, as Schneider (1966: 5) says, in the mid sixties, 85 percent of CPE terms came from English, 13 percent from indigenous languages and 2 percent from other languages, including French and Portuguese. According to Ayafor (2000: 2), this situation changed significantly by the early seventies where 80 percent of CPE lexicon was English-based, 14 percent came from indigenous languages, 5 percent from French and 1 percent from other languages. Such a drastic change can be attributed to the political evolution of the country, since Cameroon moved from a federation to a unitary state in which both Anglophones and Francophones henceforth had freedom of movement.

As Féral, (1980: 46) points out, CPE is no longer perceived exclusively as a lingua franca of the Anglophone population, but as a language with a possible national dimension. This is because its influence is felt in several major towns of the eight Francophone provinces where it is also widely spoken, and the two Anglophone provinces which initially used it. In urban as well as rural areas, CPE is used in churches, in market places, in motor parks, in railway stations, in the street, as well as in other informal situations. In fact, this 'no man's language' continues to be very present in the daily socioeconomic lives of the Cameroon people, serving as a bridge between Cameroonians of various walks of life.

\section{Usefulness of Cameroon Pidgin English}

Various studies on the language situation in Cameroon have shown the presence of loan words from CPE to the other languages, both in spoken and written forms. The rapid expansion of CPE in both written and spoke forms shows the place of CPE in Cameroon. CPE is spoken in all parts of Cameroon, by both the English speaking and French speaking Cameroonians.

$\mathrm{CPE}$ is one of the commonly used languages of wider communication in Cameroon. During the colonial period, it enabled European colonizers to interact with the indigenous population and facilitated communication among people from various ethnic groups in social, economic, and religious contexts. Today, it remains the language of daily interaction in informal situations and one of the preferred languages of popular music. It is used in humorous situations and for making jokes.

$\mathrm{CPE}$ is considered by many Cameroonians as a language for national unity. Given that language is one of the most crucial elements for nationhood, it is but logical that since CPE is spoken by almost all Cameroonians it can serve as a unifying factor in the country. Taking this into consideration, it is natural to assume that CPE plays the role of national unity as each Cameroonian identifies with it.

Similarly, CPE serves as a mother-tongue to many Cameroonians. The dynamism and range of CPE has made this lingua franca a major language in the Cameroon linguistic scene. CPE, like other pidgins in the world, is as a result of the coming together of people who do not share a common language but are forced to communicate. In the English speaking part of Cameroon, for instance, the English language was the only foreign language spoken by the foremen in the plantations. Thus, as the natives struggled to communicate with their British masters, CPE stabilised itself. As it stabilised, this language that developed as a casual means of communication gradually became the main language of socialisation for many Cameroonian children living in the South and North West provinces and in other major cities. As Neba, et al. (2006: 51) put it, children in major Anglophone towns in Cameroon have acquired CPE as a Mother-tongue. This is supported among others by Ayafor (2006) who observes that for many families in Cameroon, and in homes where the father and mother do not come from the same ethnic group or linguistic background and also have a low level of education, especially in the Anglophone region of the country, Kamtok (CPE) is the mother tongue of the children.

Given the fact that CPE serves as a mother-tongue to many Cameroonian children, it can be used as a tool to empower childhood education in Cameroon. According to UNESCO (1953), the prima facie evidence that a child learns better and faster is if that child is taught in his or her mother tongue (MT) or home language in the first year of schooling, and as far up the academic ladder as possible. This report has triggered scholarly endeavour with respect to developing and using African indigenous 
languages in education. This effort has however faced several challenges, especially in urban areas, for a good number of reasons. One of the reasons is that in urban areas of multilingual societies like the case of Cameroon, a single classroom can have children with more than twenty different linguistic backgrounds. It therefore becomes difficult to make a choice on the languages to be used. In addition, many children in urban areas in Cameroon hardly ever speak Cameroonian indigenous languages. If $\mathrm{CPE}$ is encouraged, but not necessarily replacing it with the indigenous languages, it would certainly empower the Cameroonian child if they are taught in this language which they understand and know best.

CPE can equally be considered as the best tool for empowering the adult Cameroonians, as is the case with children. For any nation to grow and survive there is need to empower its population, both the young and the old. Today, many African countries are lagging behind in terms of economic and social development due to little or no empowerment of their population. This is because most of these countries do not take into consideration linguistic factors when establishing policies for national development. Many adults in Cameroon are illiterates who can, however, be empowered through adult education. But this is somehow impossible because most of them neither speak nor understand the two official languages (French and English) used as the medium of instruction in education. If education is considered the most appropriate medium for sensitisation, then they should be taught in the language that they know. In other words, as Neba et al. (2006: 57) say, whatever strategy is adopted to ensure national development, be it through popular theatre, lectures or formal education, an appropriate language is required, and the language most suited is the one that is best understood and spoken by the target population, in this case the CPE. The language question becomes the key issue for any developmental effort. Taking this into consideration, the empowerment of the adult illiterate population of Cameroon can be possible only if Cameroonians are sensitised through adult education, using CPE which as of now seems to be the most appropriate language for use in the mass education of the Cameroonian adult illiterate population.

\section{Situating Cameroon Pidgin English in Cameroon}

As mentioned earlier, CPE is used across the board, and appears in all functional domains in Cameroon. Following Schröder (2003: 181), there are numerous extended functions of CPE serving all Cameroonians. Below are some of them.

CPE belongs to no ethnic group; it is used by all and in diverse ways, although varieties do exist. Thus, no ethnic rivalry would be engendered through its use. This language would serve as a factor for unity, as argued in Ayafor (2000: 3), in that it would bring many Cameroonians together under one common umbrella language, which none of the ethnic groups would claim as belonging to them.

Cameroon, as already mentioned, has a very diverse language situation with over 286 languages spoken across the country. This gives rise to the problem of multiplicity. If CPE is used, the problem of multiplicity of languages will not arise. Only one language will be used in the classroom. As we have already shown above, many children in urban centres speak or at least understand CPE, so introducing it as a medium of instruction would present little difficulty. The few who do not have it as a mother-tongue would easily become acquainted with its use. They would not be learning an entirely new language, as would be the case with the use of Standard English or French as a medium of instruction.

Besides these advantages for the nation, CPE could serve as a trans-border language (Chumbow, 2002). In other words, it could be developed and used to unify many African countries. This is because there are forms of Pidgin English all over Africa, in former British colonies such as Nigeria and Ghana, and they are mutually intelligible because societal perceptions about these pidgin Englishes are similar across the three countries. These different forms of Pidgin English which now serve as dialects could serve as a mark of identity for many Africans, once developed. In an era of globalisation, such a language could serve as a global language for Africans. Stories abound of how Africans from different countries have met in Europe and America and have had to communicate using the Pidgin English. In such situations, they speak the language with pride, to the admiration of non-Africans. In circumstances of this sort, there is no longer a question of Francophone or Anglophone Cameroonian; or of Anglophone or Francophone African; or of Cameroonian, Nigerian or Ghanaian. All these boundaries are abolished. 
Related to the issue of globalisation mentioned above, CPE could be beneficial to the tourism industry, as manuals could be produced in CPE for tourists to learn as a medium of communication in many Cameroonian communities. In other words, if a tourist wished to visit a number of different linguistic communities, he would not need to learn the languages of these communities for initial communication. He would not need to travel with different interpreters through the various language communities. He could start with $\mathrm{CPE}$, which has no linguistic boundaries, as a medium of communication. Although the multilingual nature of Cameroon is itself a tourist attraction, the use of $\mathrm{CPE}$ as an initial language of communication in Cameroon is recommended, given its wide usage.

\section{Conclusion}

In this paper it has been shown that Cameroon Pidgin English is a language of its own and that its development and use could solve many problems. The paper suggests that CPE should be considered as one of the indigenous languages found in Cameroon, since it is a Mother Tongue for many Cameroonian children. CPE should also be used extensively in the education of adults with all educational materials and tools written in it, and could be widely incorporated as the main language for popular theatre. If there are enough written material and text books on CPE, it will be an appropriate language for use as a medium of instruction in the early years of schooling. The language should also be used in TV and radio programmes. In so doing, a wider audience could be reached and many more people would get the messages being propagated.

Since CPE is widely used in Cameroon, it could be adopted for Cameroon literature, that is, Cameroon writers could use CPE to reach out to a wider audience. This will go a long way to arrest or reduce the writer's fright of English which is considered a difficult foreign language. With literature in CPE, many Cameroonians would be able to read and be aware of what is happening around them.

With the advent of globalization, CPE could serve as one of the main languages in the tourism industry in Cameroon. It could also be used as a trans-border language, useful in the construction of identity and in the maintenance of peace and stability, as argued by Chumbow (2002). In this regard, the CPE should be seen as a blessing in disguise because its existence helps in eliminating the problems associated with communication. Most Cameroonians, for instance, are more comfortable using this language, which they consider to be an indigenous language, than using either French or English which to them are foreign languages.

This paper purports that CPE is a more natural and unifying language which "grows" in the eyes of all Cameroonians and which transcends geographical and political boundaries, because it is not a language of a particular ethnic group and thus goes beyond the reproach of tribalism. The paper recommends that work should be undertaken to carefully synchronise the linguistic work that has been done on CPE so that a single recognised standard can be produced. The development and use of CPE will obviously lead to the empowerment of all Cameroonians.

\section{REFERENCES}

Ayafor, M. 2000. Kamtok: The ultimate unifying language for Cameroon. The Carrier Pidgin, 28: 13. International University, Florida.

Ayafor, M. 2006. Kamtok (Pidgin) is gaining ground in Cameroon. In (E. Chia ed.) African Linguistics and the Development of African Communities. CODESRIA, Senegal.

Chumbow, B. S. 2002. Transborder Languages of Africa. Paper presented at the 23rd Congress of WALS, Buea, Cameroon.

Chumbow, B. S. and A. Simo-Bobda 2000. "French in West Africa: A Sociolinguistic Perspective". Special issue of the International Journal of the Sociology of Language (IJSL) 141, 2000, pp.3960.

Bitja'a Kody, Z. D. 2001. Emergence et Survie des Langues Nationales au Cameroon. Trans No. 11/2001. Internet-Zeitschrift fur Kulturwissenchaften.

Echu, G. 2004. The Language Question in Cameroon. Linguistik Online 18, 19-34.

Epoge, Napoleon Kang. 2012. "Slang and Colloquialism in Cameroon English Verbal Discourse". International Journal of Linguistics (IJL)

Feral, C. 1989. Pidgin-English du Cameroun. Description Lingustique et Sociolinguistique. Peeters/Selaf, Paris. 
Grimes, B.F. ed. 2002. Ethnologue: Languages of the World, 14th edition. Summer Institute of Linguistics, Dallas.

Kouega, Jean-Paul (2001). Pidgin facing death in Cameroon. Terralingua. Web site: http://www.terralingua.org/DiscPapers/DiscPaper17.html accessed on the 5th August 2014 at $4 \mathrm{pm}$

Kouega, Jean-Paul (2007). The language situation in Cameroon. Current Issues in Language Planning (CILP), 8(1): 1-9.

Mbufong, P. K. 2001. Pidgin English in Anglophone Education. English Today, 17(3): 52-54.

Neba A. N., E. F Chibaka., \& G. G. Atindogbe. 2006. Cameroon Pidgin English (CPE) as a tool for Empowerment and National development. African Study Monographs, 27(2): 39-61

Ngome, M. 1986. Cameroon Pidgin English Vocabulary: A Lexico-Semantic Study. Dissertation, University of Yaounde, Cameroon.

Schneider, G. 1963. First Steps in Wes-kos. Harford Studies in Linguistics, 6(11-81): 4.

Schröder, A. 2003. Status, Functions, and Prospects of Pidgin English. An Empirical

Approach to Language Dynamics in Cameroon. Gunter Narr Verlag: Tübingen.

Todd and M. Jumbam 1992. Kamtok: Anatomy of a Pidgin. English Today, 8(1): 3-11.

\section{AUTHOR's BIOGRAPHY}

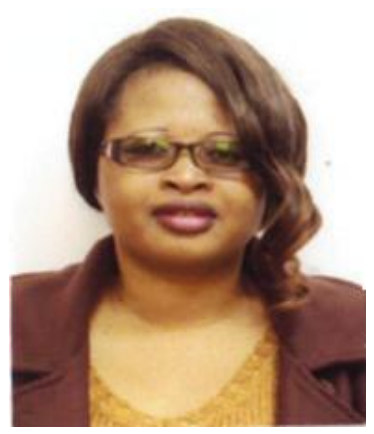

Prof. Beatrice Ekanjume-Ilongo did her tertiary education in the University of Yaounde 1, Cameroon where she obtained a $\mathrm{PhD}$ in Linguistics in 2006. Sheis currently the Dean of the Faculty of Humanities at the National University of Lesotho. She has previously worked in the universities of Yaounde 1, Cameroon and Burundi. Her research interests include Phonetics, Phonology, Morphology, Sociolinguistics, African Linguistics, Error Analysis, Onomastics, Communication and Pragmatics. Prof. Ekanjume-Ilongo is a member of the West African Linguistic Society, African Linguist Network, Names Society of Southern Africa, AILA Africa ReN (Applied Linguistics and Literacy in Africa and the Diaspora), Linguistic Association of SADC Universities, and Cameroon Association of African Linguistics. She has several accredited and refereed journal articles, and an authortwo books on Phonetics and Phonology. 